\title{
Clinical significance of amyloid $\beta$ positivity in patients with probable cerebral amyloid angiopathy markers
}

Hyemin Jang ${ }^{1,2}$, Young Kyoung Jang ${ }^{1,2}$, Hee Jin Kim ${ }^{1,2}$, David John Werring ${ }^{3}$, Jin San Lee ${ }^{4}$, Yeong Sim Choe ${ }^{1}$, Seongbeom Park ${ }^{1}$, Juyeon Lee ${ }^{5}$, Ko Woon Kim ${ }^{6}$, Yeshin Kim ${ }^{7}$, Soo Hyun $\mathrm{Cho}^{1,2}$, Si Eun $\mathrm{Kim}^{8}$, Seung Joo Kim ${ }^{1,2}$, Andreas Charidimou ${ }^{9}$, Duk L. Na ${ }^{1,2,10}$, Sang Won Seo, $\mathrm{MD}, \mathrm{PhD}^{1,2,10}$

${ }^{1}$ Departments of Neurology, Samsung Medical Center, Sungkyunkwan University School of Medicine, Seoul, Korea; ${ }^{2}$ Neuroscience Center, Samsung Medical Center, Seoul, Korea;

${ }^{3}$ UCL Stroke Research Centre, Department of Brain Repair and Rehabilitation, UCL Institute of Neurology and the National Hospital for Neurology and Neurosurgery, London, UK;

${ }^{4}$ Departments of Neurology, KyungHee University School of Medicine, Seoul, Korea; ${ }^{5}$ Department of neurology, Chungnam National University School of Medicine, Daejeon, Korea;

${ }^{6}$ Department of neurology, Chonbuk National University Hospital, Chonbuk National University Medical school, Jeonju, Korea; ${ }^{7}$ Department of Neurology, Kangwon National University Hospital, Kangwon National University College of Medicine, Chuncheon, Korea; ${ }^{8}$ Departments of Neurology, Inje University College of Medicine, Haeundae Paik Hospital, Busan, Korea; ${ }^{9}$ Department of Neurology, Massachusetts General Hospital Stroke Research Center, Harvard Medical School, Boston, MA, USA; ${ }^{10}$ Department of Health Sciences and Technology, SAIHST, Sungkyunkwan University

Corresponding author:

Sang Won Seo, MD, PhD

Department of Neurology, Sungkyunkwan University School of Medicine, Samsung Medical Center, 81 Irwon-ro, Gangnam-gu, Seoul 06351, Republic of Korea

Tel.: +82-2-3410-6147, Fax: +82-2-3410-0052 
E-mail: sangwonseo@empal.com or sw72.seo@samsung.com

\section{Disclosures}

All authors have no conflicts of interest to disclose.

\section{Acknowledgements}

SWS receives funding from the Brain Research Program through the National Research Foundation of Korea (2016M3C7A1913844) and from the Korea government (MSIP) through the National Research Foundation of Korea grant (2017R1A2B2005081)

\section{ABSTRACT}

Purpose We investigated the frequency and clinical significance of amyloid $\beta(A \beta)$ positivity on PET in cerebral amyloid angiopathy (CAA) patients.

Methods We recruited 65 patients who met the modified Boston criteria for probable CAA. All underwent amyloid PET, MRI, APOE genotyping and neuropsychological tests, and we obtained information of CAA and ischemic cerebral small vessel disease (CSVD) MRI markers. We investigated the CAA/ischemic CSVD burden and APOE genotypes by A $\beta$ positivity and investigated the effect of $A \beta$ positivity on longitudinal cognitive decline. Results Among 65 CAA patients, 43(66.2 \%) showed A $\beta$ PET positivity $(+)$. A $\beta+$ CAA had more lobar microbleeds $(9(2,41)$ vs. $3(2,8), p=0.045)$ and a higher frequency of cortical superficial siderosis(34.9 vs. $9.1 \%, p=0.025)$, while $A \beta$ - CAA had more lacunes( $(1(0,2)$ vs. $0(0,1), p=0.029)$ and a higher frequency of severe white matter hyperintensities(45.5 vs. $20.9 \%, p=0.040)$. The frequency of $\varepsilon 4$ carriers was higher in $\mathrm{A} \beta+(57.1 \%)$ than in $\mathrm{A} \beta$ CAA $(18.2 \%)(p=0.003)$ while the frequency of $\varepsilon 2$ carriers did not differ between two groups. Finally, $A \beta$ positivity was associated with faster decline in multiple cognitive domains including language $(p<0.001)$, visuospatial function $(p<0.001)$, and verbal memory $(p<0.001)$ in linear mixed effects models. 
Conclusions Our findings suggest that a significant proportion of probable CAA patients in a memory clinic are $\mathrm{A} \beta$ PET negative. $\mathrm{A} \beta$ positivity in CAA patients is associated with a distinct pattern of CSVD biomarker expression, and a worse cognitive trajectory. A $\beta$ positivity has clinical relevance in CAA and might represent either advanced CAA or additional Alzheimer's disease neuropathologic changes.

Keywords: Cerebral amyloid angiopathy, Amyloid $\beta$, Amyloid $\beta$ PET 


\section{Introduction}

Cerebral amyloid angiopathy (CAA) is characterized by amyloid $\beta(\mathrm{A} \beta)$ deposition in small arteries of meninges and cortex, leading to vascular dysfunction and brain tissue injury. CAA magnetic resonance imaging (MRI) markers including strictly lobar intracerebral hemorrhage (LICH), lobar cerebral microbleeds (CMBs) and cortical superficial siderosis (cSS) have been validated and accepted in Boston criteria[1, 2]. A recent study further suggested that $90 \%$ of symptomatic CAA patients diagnosed by the presence of multiple lobar CMBs without lobar ICH in a hospital-based setting harbored moderate to severe CAA on neuropathology[3]. Recent studies investigated the clinical utility of A $\beta$ PET in patients with probable CAA MRI markers. Probable CAA patients had a significantly higher Pittsburgh Compound-B (PiB) uptake compared with normal controls, in occipital regions where CAA typically shows a predilection[4, 5] compared with Alzheimer's disease (AD) $[6,7]$. It has thus been suggested that $\mathrm{A} \beta$ PET has moderate to good accuracy for diagnosis of CAA (such that an $\mathrm{A} \beta$ negative (-) PET scans might rule out CAA), at least in patients with symptomatic $\operatorname{LICH}[4,5,8,9]$.

CAA is present in over $80 \%$ of the brains of patients with $\mathrm{AD}[10,11]$. By contrast, while CAA can be associated with $\mathrm{A} \beta$ parenchymal aggregates such as neuritic and diffuse plaques $[12,13]$, it can also occur pathologically without evident AD neuropathologic changes $(\mathrm{ADNC})[14,15]$. Therefore, it might be reasonable to expect that some patients with probable CAA MRI markers might be $A \beta$ - on PET. By contrast, $A \beta$ positivity in patients with CAA MRI markers might identify more advanced CAA pathology, or concomitant ADNC considering that it might be more difficult to differentiate from underlying incipient $\mathrm{AD}$ if $\mathrm{A} \beta$ PET positive $(+)[8]$, particularly in memory clinic.

A large body of evidence has emphasized the clinical significance of A $\beta+$ PET scans on cognition in neurodegenerative diseases; for example, $\mathrm{A} \beta+$ mild cognitive impairment (MCI) patients are more likely convert to $\mathrm{AD}$ than $\mathrm{A} \beta$ - patients [16]. Moreover, we have shown that $\mathrm{A} \beta$ burden is associated with cognitive decline in patients with both $\mathrm{AD}$ related 
and vascular cognitive impairment, suggesting that $A \beta$ and ischemic cerebral small vessel disease (CSVD) have additive effects on cognitive decline[17-19]. Although CAA can present with clinical phenotypes other than symptomatic LICH, including cognitive impairment[20], $\mathrm{A} \beta$ PET is largely unexplored in such patients.

In the present study, we investigated clinical significance of $A \beta$ positivity on PET in patients with probable CAA MRI markers, referred as CAA patients, who primarily visited a memory clinic. We hypothesized that CAA patients might be classified into $A \beta+$ and $A \beta$ - on PET, and that $A \beta+C A A$ patients might have more MRI-defined CAA markers and worse cognitive function and trajectories than $\mathrm{A} \beta$ - CAA patients.

\section{Materials and Methods}

\section{Study subjects}

We included all eligible patients who visited a memory clinic in Samsung Medical Center complaining of cognitive impairment and underwent either PiB (from July 2007 to July 2011) or florbetaben (from August 2015 to September 2016) scans. A total of 1,027 (253 for PiB and 774 for florbetaben) participants were prospectively recruited. Then, we scrutinized brain MRI of all patients and identified only 65 patients (15 PiB PET, 50 florbetaben PET) with probable CAA, who have at least two strictly LICH/lobar CMBs or one strictly LICH/lobar CMB with cSS on MRI as according to modified Boston criteria[21, 22]. Among 65 CAA patients, 59 patients (including four patients with asymptomatic LICH) presented with cognitive impairment and six patients presented with symptomatic LICH and were referred to our clinic for their cognitive impairment. The remaining 962 patients were diagnosed as cognitively normal ( $\mathrm{n}=148)$, Alzheimer's disease related cognitive impairment[23] (amnestic MCI and $\mathrm{AD}, \mathrm{n}=530$ ), subcortical vascular cognitive impairment[23] $(\mathrm{n}=184)$, or other dementia syndrome $(\mathrm{n}=101)$. As a control group in this study, we included $129 \mathrm{~A} \beta+\mathrm{AD}$ patients. These patients underwent florbetaben PET scans from August 2015 to September 2016 at Samsung Medical Center, and clinically met the 
criteria for probable AD dementia according to National Institute on Aging and the Alzheimer's Association criteria[24].We excluded patients with the presence of secondary causes of cognitive deficits (e.g., vitamin $\mathrm{B}_{12}$ /folate, syphilis serology, and/or thyroid dysfunction), or structural lesions except for LICH (e.g., territorial cerebral infarctions and brain tumors), or with psychiatric illnesses such as schizophrenia. The Institutional Review Board of Samsung Medical Center approved the study protocol and written consent was obtained from each patient.

\section{MRI acquisition}

All participants underwent brain MRI including T2* GRE, T1, three-dimensional (3D) FLAIR and 3D T1 images at Samsung Medical Center using the same kind of 3.0T MRI scanner (Philips 3.0T Achieva; Best, the Netherlands). The following parameters were used for the T2* GRE images: axial slice thickness $5.0 \mathrm{~mm}$; inter-slice thickness $2 \mathrm{~mm}$; repetition time (TR) $669 \mathrm{~ms}$; echo time (TE) $16 \mathrm{~ms}$; flip angle 18; matrix size 560x560 pixels. We acquired 3D T1 images with the following parameters: sagittal slice thickness $1.0 \mathrm{~mm}$, over contiguous slices with $50 \%$ overlap; TR 9.9 ms; TE $4.6 \mathrm{~ms}$; flip angle $8^{\circ}$; and matrix size 240 $\times 240$ pixels, reconstructed to $480 \times 480$ over a field of view of $240 \mathrm{~mm}$. 3D FLAIR images were obtained with the following parameters: axial slice thickness $2 \mathrm{~mm}$; no gap; TR 11,000 ms; TE $125 \mathrm{~ms}$; flip angle $90^{\circ}$; and matrix size $512 \times 512$ pixels.

\section{Assessment of CAA and ischemic CSVD imaging markers on MRI}

Imaging analysis was carried out by individuals who were trained in neuroimaging rating and blinded to the participant clinical details. All structural imaging markers of CSVD were rated in accordance with consensus guidelines [25]. Lobar CMBs were defined as homogenous and round lesions with signal loss ( $\leq 10 \mathrm{~mm}$ in diameter $)$ on T2* GRE images, with location in exclusively lobar areas. cSS was defined as linear hypointensities on T2* 
GRE images consistent with chronic blood residues in the superficial layers of the cerebral cortex [26]. Four experienced neurologists, who were blinded to clinical information rated lobar CMBs and cSS. The inter-observer intra-class correlation coefficient ranged from 0.87 to 0.91 for lobar CMBs and from 0.82 to 0.96 for cSS [27].

White matter hyperintensities (WMH) severity was rated using the modified Fazekas scale [28]. Periventricular WMH (PWMH) were classified as P1 (cap and band $<5$ $\mathrm{mm}), \mathrm{P} 2(5 \mathrm{~mm} \leq \mathrm{cap}$ or band $<10 \mathrm{~mm})$, or P3 (10 mm $\leq$ cap or band); and deep WMH (DWMH) were classified as D1 (maximum diameter of deep white matter lesion $<10 \mathrm{~mm}$ ), D2 $(10 \mathrm{~mm} \leq$ lesion $<25 \mathrm{~mm})$, and D3 $(\geq 25 \mathrm{~mm})$. Severe $\mathrm{WMH}$ was defined as periventricular $\mathrm{WMH} \geq 10 \mathrm{~mm}$ and deep $\mathrm{WMH} \geq 25 \mathrm{~mm}$. Lacunes were identified and counted in accordance with STRIVE (STandards for ReportIng Vascular changes on nEuroimaging) [25].

\section{A $\beta$ PET imaging acqusition}

All patients underwent A $\beta$ PET using a Discovery STe PET/CT scanner (GE Medical Systems, Milwaukee, WI) in a 3D scanning mode that examined 47 slices of $3.3 \mathrm{~mm}$ thickness spanning the entire brain. A 16-slice helical CT (140 KeV, $80 \mathrm{~mA} ; 3.75 \mathrm{~mm}$ section width) was performed for attenuation correction. For ${ }^{11} \mathrm{C}-\mathrm{PiB}$ PET, a 30-minute emission static PET scan was performed 60 minutes after injection into an antecubital vein as a bolus of a mean dose of $420 \mathrm{MBq}$. For ${ }^{18}$ F-Florbetaben PET, a 20-minute emission PET scan with dynamic mode (consisting of 4 x 5 min frames) was performed 90 minutes after injection into an antecubital vein as a bolus of a mean dose of $381 \mathrm{MBq}$.

\section{A $\beta$ PET image preprocessing and interpretation}

Both MR and PET images were co-registered with each other using the rigid-body transformation. The T1-weighted MR image of each subject was aligned with the MNI-152 template using a non-linear deformation including translation, rotation, scaling and shearing. After standard space registration, we divided grey matter into 116 regions using the 
Automated Anatomical Labeling (AAL) atlas [29]. In order to compute standardized uptake value ratios (SUVR), every voxel intensity was normalized by the mean intensity of cerebellar gray matter which was regarded as reference region.

Global $\mathrm{A} \beta$ PET (PiB and florbetaben PET) retention ratios were assessed from the volume-weighted average SUVR of 28 bilateral cerebral cortical volume of interests (VOIs). We defined $\mathrm{A} \beta$ PET to be positive $(\mathrm{A} \beta+)$ when the global PiB SUVR was greater than 1.5 or when florbetaben PET was visually rated as 2 or 3 on the brain A $\beta$ plaque load (BAPL) scoring system [30].

We also obtained regional cortical florbetaben SUVR, especially frontal (superior and middle frontal gyri, medial part of superior frontal gyrus, opercular part of inferior frontal gyrus, triangular part of inferior frontal gyrus, supplementary motor area, orbital part of superior, middle, and inferior orbital frontal gyri, rectus and olfactory cortex) and occipital (superior, middle, and inferior occipital gyri, cuneus, calcarine fissure, and lingual and fusiform gyri) SUVR, and calculated occipital/global and frontal/global SUVR ratio to demonstrate the distribution of florbetaben retention.

\section{Neuropsychological tests}

All patients underwent neuropsychological tests using the Seoul neuropsychological Screening Battery (SNSB) [27, 31], which consists of tests for attention, language, visuoconstructive function, verbal and visual memory, and frontal/executive function. We obtained retrospective and prospective neuropsychological test results from these patients, all of whom conducted the complete SNSB at least once at time of PET imaging. We used quantitatively scorable tests in the analysis; therefore,digit span forward (total: 9) and backward (total:8) scores for attention domain, the Boston Naming Test (BNT) scores (total: 60) for language domain, the Rey-Osterrieth Complex Figure Test (RCFT) copy score (total: 36) for visuospatial domain, the Seoul Verbal Learning Test (SVLT)/RCFT immediate score (total:36), delayed recall score (total: SVLT 12, RCFT 36) and recognition score (total: 24) 
for memory domain, a phonemic and semantic Controlled Oral Word Association Test (COWAT) score (total: unlimited), a Stroop test color reading score (total: 120) for frontal/executive domain, Mini-mental state examination (MMSE, total:30), and clinical dementia rating - sum of boxes (CDR-SOB) were included in the analysis.

\section{Statistical analyses}

To investigate the pairwise differences in demographics and clinical characteristics (including frequency of apolipoprotein $\mathrm{E}(A P O E) \varepsilon 4$ or $\varepsilon 2$ carriers) between three groups ( $\mathrm{A} \beta$ - CAA, $A \beta+C A A$, and $A \beta+A D)$, student's t-tests and $\chi 2$ tests were used. In order to compare the frequency of $A P O E \varepsilon 4$ or $\varepsilon 2$ carriers between three groups $(\mathrm{A} \beta-\mathrm{CAA}, \mathrm{A} \beta+\mathrm{CAA}$, and $\mathrm{A} \beta+\mathrm{AD}$ ) or between CAA patients with and without hemorrhagic imaging markers, we performed $\chi^{2}$ tests. To compare pairwise differences in florbetaben retention distribution between three groups ( $\mathrm{A} \beta-\mathrm{CAA}, \mathrm{A} \beta+\mathrm{CAA}$, and $\mathrm{A} \beta+\mathrm{AD})$, we performed analysis of covariance (ANCOVA) using age, gender and MMSE as covariates. Comparison of CAA and ischemic CSVD markers between A $\beta$ - CAA and A $\beta+$ CAA were performed using wilcoxon ranksum tests for continuous variables (because of the skewed distribution of data) and $\chi^{2}$ tests for dichotomous variables. Finally, to compare cognition (SNSB scores) between A $\beta$ and $\mathrm{A} \beta+\mathrm{CAA}$, we also performed ANCOVA using age, gender and education as covariates.

To investigate the effect of $A \beta$ positivity on longitudinal cognitive changes, linear mixed effect model was conducted. Fixed effects were A $\beta$ positivity, time from the PET study, age, gender, education years, and the two-way interaction term for A $\beta$ positivity and time (A $\beta$ positivity * time). Patients were included as random effects. All statistical analyses were performed with STATA/SE version 15.1. Statistical significance was defined as twotailed $P<0.05$.

\section{Results}

\section{Demographics and clinical characteristics of participants}


Among 65 CAA patients, 43 (66.2 \%) showed A $\beta$ PET positivity (A $\beta+$ CAA). The frequency of A $\beta$ PET positivity did not differ between two PET cohorts; 10 of 15 PiB PET (66.7\%) and 33 of 50 florbetaben PET (66\%) were $A \beta+$.

$\mathrm{A} \beta$ - $\mathrm{CAA}(75.3 \pm 7.1)$ and $\mathrm{A} \beta+\mathrm{CAA}(74.4 \pm 8.1)$ were older than $\mathrm{A} \beta+\mathrm{AD}$ without CAA imaging markers $(67.1 \pm 10.2)(P<0.001$ and $P<0.001)$. A $\beta+$ CAA $(53.5 \%)$ were more likely to have hypertension than $\mathrm{A} \beta+\mathrm{AD}(37.2 \%)(P=0.016)$, and $\mathrm{A} \beta-\mathrm{CAA}(36.4 \%)$ were more likely to have diabetes than $\mathrm{A} \beta+\mathrm{AD}(14.0 \%)(P=0.002)$. There were no differences in other demographics and clinical data across three groups (Table 1).

The frequency of $A P O E \varepsilon 4$ carriers and $\varepsilon 2$ carriers by $A \beta$ positivity and the presence of CAA hemorrhagic markers

The frequency of $\varepsilon 4$ carriers was higher in $\mathrm{A} \beta+\mathrm{CAA}(57.1 \%)$ than in $\mathrm{A} \beta$ - CAA $(18.2 \%)(P=0.003)$ while it did not differ between $\mathrm{A} \beta+\mathrm{CAA}(57.1 \%)$ and $\mathrm{A} \beta+\mathrm{AD}$ without CAA imaging markers $(56.3 \%)(P=0.901)$. The frequency of $\varepsilon 2$ carriers was higher in A $\beta$ CAA $(18.2 \%)$ or $\mathrm{A} \beta+\mathrm{CAA}(14.3 \%)$ than in $\mathrm{A} \beta+\mathrm{AD}(5.2 \%)(P=0.031$ and 0.002$)$, but it did not differ between $\mathrm{A} \beta$ - and $\mathrm{A} \beta+\mathrm{CAA}$. (Fig. 1a)

The frequency of $\varepsilon 2$ carriers was higher in $\mathrm{LICH}+(5 / 10,50 \%)$ than in $\mathrm{LICH}$ - group $(6 / 54,11.1 \%)(P=0.003)$ while the frequency of $\varepsilon 4$ carriers was higher in LICH- $(27 / 54$, $50 \%)$ than in LICH+ group $(1 / 10,10 \%)(P=0.019)$ (Fig. 1b). Similarly, the frequency of $\varepsilon 2$ carriers was significantly higher in cSS $+(6 / 17,35.3 \%)$ than in cSS- group $(5 / 47,10.6 \%)(P=$ $0.021)$ but the frequency of $\varepsilon 2$ carriers did not differ between cSS+ (35.3\%) and cSS- group $(46.8 \%)(P=0.412)($ Fig. 1C)

\section{A $\beta$ uptake pattern of CAA}

When we compared A $\beta$ PET uptake patterns between $A \beta+C A A(n=33$, florbetaben only) and $\mathrm{A} \beta+\mathrm{AD}$ without $\mathrm{CAA}$ imaging markers ( $\mathrm{n}=129$, florbetabepn), occipital/global ratio was higher in $\mathrm{A} \beta+\mathrm{CAA}(0.97 \pm 0.06)$ than in $\mathrm{A} \beta+\mathrm{AD}(0.95 \pm 0.06)(P=0.045)$, while frontal/global ratio did not differ between $\mathrm{A} \beta+\mathrm{CAA}(0.99 \pm 0.04)$ and $\mathrm{A} \beta+\mathrm{AD}(1 \pm 0.04)(P=$ 
0.092) after adjusting for age, gender and MMSE scores (Fig. 2). Furthermore, when we compared A $\beta$ PET uptake patterns between $A \beta-C A A(n=17$, florbetaben only) and $A \beta+A D$, A $\beta$ - CAA (1.04 \pm 0.04$)$ showed a higher occipital/global ratio than $\mathrm{A} \beta+\mathrm{AD}(0.95 \pm 0.06)(P<$ $0.001)$ while $\mathrm{A} \beta$ - CAA $(0.96 \pm 0.04)$ showed lower frontal/global ratio than $\mathrm{A} \beta+\mathrm{AD}(1 \pm 0.04)$ $(P<0.001)$ (Fig. 2).

\section{CAA and ischemic CSVD markers by A $\beta$ positivity}

Compared with A $\beta$ - CAA, A $\beta+$ CAA patients had more lobar $\operatorname{CMBs}(9(2,41)$ vs. 3 $(2,8), P=0.045)$ and a higher frequency of $\operatorname{cSS}(34.9$ vs. $9.1 \%, P=0.025)$. In contrast, A $\beta-$ CAA patients had more lacunes $(1(0,2)$ vs. $0(0,1), P=0.029)$ and a higher frequency of severe WMH ( $45.5 \%$ vs. $20.9, P=0.040)$ than $\mathrm{A} \beta+$ CAA patients. The frequency of LICH did not differ between the two groups $(P=0.655)$ (Table 2). Detailed imaging and clinical characteristics of $A \beta-C A A$ patients are shown in Table 3. Images from typical A $\beta$ - $C A A$ patients are shown in Fig. 3.

\section{Distinct cognitive trajectory by $\mathrm{A} \beta$ positivity}

Neuropsychological tests at time of PET study showed that A $\beta+$ CAA patients had significantly worse performances on the BNT $(30.4 \pm 12.7$ vs. $37.7 \pm 9.5, P=0.014)$ and the $\operatorname{MMSE}(19.7 \pm 6.3$ vs. $22.8 \pm 5.0, P=0.038)$ than $A \beta$ - CAA patients (Table 3$)$.

A total of 42 of 65 patients underwent at least one follow-up visit for neuropsychological tests. The average number of neuropsychological tests follow-up was 3.8 \pm 1.4 . In linear mixed effects models to investigate the effects of $A \beta$ positivity on cognitive decline, $\mathrm{A} \beta$ positivity was associated with faster decline in the following tests: BNT $(P<$ 0.001), RCFT copy $(P<0.001)$, SVLT immediate recall $(P<0.001)$, RCFT immediate recall $(P=0.005)$, RCFT delayed recall $(P<0.001)$, COWAT supermarket $(P=0.001)$, Stroop test color reading $(P=0.001)$, MMSE $(P<0.001)$, and CDR-SOB $(P<0.001)$ (Table 4, Fig. 4$)$.

\section{Discussion}


Using noninvasive amyloid imaging and structural MRI for markers of CSVD, we report distinct clinical and MRI characteristics of patients with probable CAA according to A $\beta$ positivity status on PET. Our main findings are that: first, a significant proportion of patients with probable CAA seen in a memory clinic are A $\beta$ PET negative; second, $\mathrm{A} \beta$ positivity in CAA patients is associated with a distinct pattern of MRI small vessel disease biomarker expression; and third, $\mathrm{A} \beta$ positivity in CAA is associated with a worse cognitive trajectory. Taken together, our findings suggested that $A \beta$ positivity has mechanistic and clinical relevance in CAA and might represent either advanced CAA or additional ADNC.

Our first major finding was that $A \beta$ positivity was found in $67 \%$ of patients with probable CAA. Our finding is partially consistent with previous studies. Specifically, some studies suggested that about $60 \%$ [32] or $70 \%[33]$ of probable CAA patients had A $\beta$ PET positivity while other studies showed relatively high sensitivity ( $80 \%$ to $100 \%)$ of A $\beta$ PET in probable CAA [4-6, 34] (Table 5). The discrepancy between previous studies and our study may be partly explained by smaller sample size of previous studies and different study participants (primarily patients with restricted multiple lobar CMBs from memory clinic in our sample compared with non-demented patients with only symptomatic LICH in those studies) as CAA with and without LICH might have different pathophysiologic mechanisms [35].

The reason that about $30 \%$ of patients who have characteristic CAA MRI markers were A $\beta$ - on PET was important. There might be several explanations. First, current amyloid PET tracers cannot differentiate vascular $A \beta$ from parenchymal $A \beta$. However, a previous study revealed that pathologically proven CAA cases had increased occipital/global ratio relative to $\mathrm{AD}$ cases [34]. In fact, in the present study, while $\mathrm{A} \beta$ - CAA had lower frontal/global ratio than $\mathrm{A} \beta+\mathrm{AD}, \mathrm{A} \beta-\mathrm{CAA}$ as well as $\mathrm{A} \beta+\mathrm{CAA}$ had higher occipital/global ratio than $\mathrm{A} \beta+\mathrm{AD}$. Thus, increased occipital/global ratio in CAA patients regardless of $\mathrm{A} \beta$ positivity might reflect vascular $A \beta$ uptake. Second, A $\beta$ - CAA patients might have mild ADNC because $A \beta$ PET has a limitation that it shows low accuracy in detecting mild ADNC [36]. Indeed, pathologic studies suggested that less than $50 \%$ of CAA patients meet 
pathological criteria for $\mathrm{AD}[37,38]$.

We found that frequency of $A P O E \varepsilon 2$ carriers was significantly higher in $\mathrm{A} \beta+\mathrm{CAA}$ or $\mathrm{A} \beta$ - $\mathrm{CAA}$ patients than in $\mathrm{A} \beta+\mathrm{AD}$ patients, although the frequency of $A P O E \varepsilon 2$ carriers did not differ between $\mathrm{A} \beta+\mathrm{CAA}$ and $\mathrm{A} \beta$ - CAA groups. Moreover, in CAA patients, the frequency of $A P O E$ \&2 carriers was significantly higher in a group with overt hemorrhagic markers such as cSS or LICH than in a group without overt hemorrhagic markers.

Considering another finding that the frequency of $A P O E \varepsilon 4$, but not $\varepsilon 2$, carriers was higher in $\mathrm{A} \beta+\mathrm{CAA}$ than in $\mathrm{A} \beta-\mathrm{CAA}, A P O E \varepsilon 4$ in CAA predict $\mathrm{A} \beta$ positivity while $A P O E \varepsilon 2$ in CAA is related to overt hemorrhagic markers of CAA. In fact, our suggestion might be supported by previous studies showing that $A P O E \varepsilon 4$ is related to deposition of $\mathrm{A} \beta$ burdens and $A P O E$ $\varepsilon 2$ is related to breakdown of blood vessel walls [35, 39].

Our second finding was that $\mathrm{A} \beta+\mathrm{CAA}$ patients had more lobar CMBs and more frequent cSS than $\mathrm{A} \beta$ - $\mathrm{CAA}$ patients. A previous study showed that increasing lobar CMB count may increase the ability to identify CAA pathology [40]. In addition, cSS is known to be a key hemorrhagic marker of CAA [21] and a previous study demonstrated that cSS reflects an $A \beta$ rather than ischemic etiology [41]. Our findings might therefore indicate that $\mathrm{A} \beta+\mathrm{CAA}$ have more $\mathrm{CAA}$ burdens than $\mathrm{A} \beta$ - $\mathrm{CAA}$. In contrast, $\mathrm{A} \beta$ - CAA have more ischemic CSVD (or deep perforator arteriopathy) markers including lacunes and WMH than A $\beta+$ CAA. Previous studies from our group suggested that lobar CMBs might be attributed to CSVD as well as A $\beta$ uptake $[42,43]$. CSVD and A $\beta$ uptake were synergistically associated with the development of lobar CMBs, although these studies included patients with combined lobar and deep CMBs. Our current findings suggest that ischemic CSVD alone or ischemic CSVD combined with CAA might contribute to some CAA MRI markers (e.g. lobar CMBs) in A $\beta$ - patients who meet criteria [21] for probable CAA based on MRI markers. For example, chronic hypertension may cause autoregulatory dysfunction of superficial perforating arteries of pial origin as well as deep perforating arteries [44], resulting in damage to the smooth muscle cells and development of CMBs in lobar areas. It is also possible that additional hypertensive CSVD burden might affect common pathways of CAA, including 
endothelial dysfunction or inflammation, which could lead to synergistically increased vulnerability to hemorrhage with less severe CAA burden.

Our final major finding was that $\mathrm{A} \beta+\mathrm{CAA}$ patients showed more rapid decline in multiple cognitive domains, compared with $\mathrm{A} \beta$ - CAA patients. A previous study from our group showed that CAA hemorrhagic markers had an adverse influence on cognition [45]. In the current study, we build on these observations by showing that $A \beta$ positivity is associated with cognitive decline in CAA patients. These findings are consistent with a previous autopsy study, which demonstrated that CAA and AD pathologies synergistically contribute to cognitive impairment [46], although relative contributions of mixed neuropathologies to cognitive impairment varied according to a recent study [47]. It is also possible that severe CAA burden alone contributed to worse cognitive decline as A $\beta$ positivity might represent advanced CAA pathology even without parenchymal A $\beta$. A possible explanation is that CAA causes ischemic injury by decreased cerebral blow flow and hypoxia, which could increase vulnerability to neuronal death due to ADNC [47].

The strengths of our study include standardized A $\beta$ PET, MRI and neuropsychological protocols. Although a sample size is not large, our study has a relatively large CAA cohort from a memory clinic compared with previous studies[4-6, 32-34] (Table 5). We are not aware of similar studies in this field that focus on probable CAA. However, some limitations need to be acknowledged. The main limitation of our study is the lack of pathological data. Thus, CAA markers were defined using only the modified Boston criteria for probable CAA. In addition, we did not utilize A $\beta$ PET for diagnosis of CAA because current amyloid ligands for PET cannot differentiate vascular A $\beta$ from parenchymal A $\beta$ burdens. Therefore, it needs to be validated in pathological studies. Finally, we included patients who underwent $\mathrm{A} \beta$ PET scans using PiB or florbetaben, which might affect our findings. However, there was no difference in the frequency of A $\beta$ positivity in CAA patients with PiB and florbetaben PET (10/15 (66.7\%) vs. 33/50 (66\%), p = 0.962). Also, a previous head-to-head study using two $A \beta$ tracers suggested that two tracers binding were highly correlated with each other $\left(R^{2}=0.96\right)[48]$. Therefore, we expect that use of different $A \beta$ 
ligands does not much affect the classification of parenchymal A $\beta$ positivity. However, further studies should be needed to investigate a difference in intensity or pattern of uptake between two ligands in CAA patients.

\section{Conclusions}

In conclusion, our findings suggest that $\mathrm{A} \beta+\mathrm{CAA}$ patients have a distinct neuroimaging signature suggesting advanced CAA or ADNC burdens, which lead to a worse cognitive status and trajectory. Our findings suggest that A $\beta$ PET has mechanistic and clinical relevance in a clinically diagnosed probable CAA population; In particular, our findings demonstrate potential clinical utility of A $\beta$ PET in predicting the prognosis of CAA patients who primarily visited a memory clinic. A $\beta$ PET might also have value for the design, patient selection and interpretation in future CAA treatment trials.

\section{Compliance with ethical standards}

Funding This research was funded by the Brain Research Program through the National Research Foundation of Korea (2016M3C7A1913844) and from the Korea government (MSIP) through the National Research Foundation of Korea grant (2017R1A2B2005081).

Conflict of interest All authors have no conflicts of interest to disclose.

Role of the funder The funders had no role in the design and conduct of the study; collection, management, analysis, and interpretation of the data; preparation, review, or approval of the manuscript; or decision to submit the manuscript for publication. Ethical approval All procedures performed in studies involving human participants were in accordance with the ethical standards of the institutional and/or national research committee and with the 1964 Helsinki declaration and its later amendments or comparable ethical standards. 
Informed consent Informed consent was obtained from all individual participants included in the study.

\section{References}

1. Knudsen KA, Rosand J, Karluk D, Greenberg SM. Clinical diagnosis of cerebral amyloid angiopathy: validation of the Boston criteria. Neurology 2001;56:537-9.

2. Linn J, Halpin A, Demaerel P, Ruhland J, Giese A, Dichgans M, et al. Prevalence of superficial siderosis in patients with cerebral amyloid angiopathy(CME). Neurology 2010;74:1346-50.

3. Martinez-Ramirez S, Romero JR, Shoamanesh A, McKee AC, Van Etten E, Pontes-Neto O, et al. Diagnostic value of lobar microbleeds in individuals without intracerebral hemorrhage. Alzheimers Dement 2015;11:1480-8.

4. Baron JC, Farid K, Dolan E, Turc G, Marrapu ST, O'Brien E, et al. Diagnostic utility of amyloid PET in cerebral amyloid angiopathy-related symptomatic intracerebral hemorrhage. J Cereb Blood Flow Metab 2014;34:753-8.

5. Gurol ME, Becker JA, Fotiadis P, Riley G, Schwab K, Johnson KA, et al. FlorbetapirPET to diagnose cerebral amyloid angiopathy: A prospective study. Neurology 2016;87:2043-9.

6. Ly J, Donnan GA, Villemagne VL, Zavala J, Ma H, O'keefe G, et al. 11C-PIB binding is increased in patients with cerebral amyloid angiopathy-related hemorrhage. Neurology 2010;74:487-93.

7. Bacskai BJ, Frosch MP, Freeman SH, Raymond SB, Augustinack JC, Johnson KA, et al. Molecular imaging with Pittsburgh Compound B confirmed at autopsy: a case report. Arch Neurol 2007;64:431-4.

8. Farid K, Charidimou A, Baron JC. Amyloid positron emission tomography in sporadic cerebral amyloid angiopathy: A systematic critical update. Neuroimage Clin $2017 ; 15: 247-63$. 
9. Charidimou A, Farid K, Baron JC. Amyloid-PET in sporadic cerebral amyloid angiopathy: A diagnostic accuracy meta-analysis. Neurology 2017.

10. Ellis R, Olichney J, Thal L, Mirra S, Morris J, Beekly D, et al. Cerebral amyloid angiopathy in the brains of patients with Alzheimer's disease The CERAD experience, part XV. Neurology 1996;46:1592-6.

11. Esiri MM, Wilcock GK. Cerebral amyloid angiopathy in dementia and old age. J Neurol Neurosurg Psychiatry 1986;49:1221-6.

12. Thal DR, Ghebremedhin E, Orantes M, Wiestler OD. Vascular pathology in Alzheimer disease: correlation of cerebral amyloid angiopathy and arteriosclerosis/lipohyalinosis with cognitive decline. Journal of Neuropathology \& Experimental Neurology 2003;62:1287-301.

13. Attems J, Jellinger KA, Lintner F. Alzheimer's disease pathology influences severity and topographical distribution of cerebral amyloid angiopathy. Acta Neuropathol 2005; 110:222-31.

14. Attems J. Sporadic cerebral amyloid angiopathy: pathology, clinical implications, and possible pathomechanisms. Acta Neuropathol 2005;110:345-59.

15. Ellis RJ, Olichney JM, Thal LJ, Mirra SS, Morris JC, Beekly D, et al. Cerebral amyloid angiopathy in the brains of patients with Alzheimer's disease: the CERAD experience, Part XV. Neurology 1996;46:1592-6.

16. Okello A, Koivunen J, Edison P, Archer H, Turkheimer F, Någren Ku, et al. Conversion of amyloid positive and negative MCI to AD over 3 years An 11C-PIB PET study. Neurology 2009;73:754-60.

17. Park JH, Seo SW, Kim C, Kim SH, Kim GH, Kim ST, et al. Effects of cerebrovascular disease and amyloid beta burden on cognition in subjects with subcortical vascular cognitive impairment. Neurobiol Aging 2014;35:254-60.

18. Kim HJ, Yang JJ, Kwon H, Kim C, Lee JM, Chun P, et al. Relative impact of amyloidbeta, lacunes, and downstream imaging markers on cognitive trajectories. Brain 2016;139:2516-27. 
19. Kim HJ, Im K, Kwon H, Lee JM, Kim C, Kim YJ, et al. Clinical effect of white matter network disruption related to amyloid and small vessel disease. Neurology 2015;85:6370.

20. Banerjee G, Carare R, Cordonnier C, Greenberg SM, Schneider JA, Smith EE, et al. The increasing impact of cerebral amyloid angiopathy: essential new insights for clinical practice. J Neurol Neurosurg Psychiatry 2017.

21. Linn J, Halpin A, Demaerel P, Ruhland J, Giese AD, Dichgans M, et al. Prevalence of superficial siderosis in patients with cerebral amyloid angiopathy. Neurology 2010;74:1346-50.

22. Greenberg SM, Charidimou A. Diagnosis of Cerebral Amyloid Angiopathy: Evolution of the Boston Criteria. Stroke 2018;49:491-7.

23. Park JH, Seo SW, Kim C, Kim GH, Noh HJ, Kim ST, et al. Pathogenesis of cerebral microbleeds: In vivo imaging of amyloid and subcortical ischemic small vessel disease in 226 individuals with cognitive impairment. Annals of Neurology 2013;73:584-93.

24. McKhann GM, Knopman DS, Chertkow H, Hyman BT, Jack CR, Jr., Kawas CH, et al. The diagnosis of dementia due to Alzheimer's disease: recommendations from the National Institute on Aging-Alzheimer's Association workgroups on diagnostic guidelines for Alzheimer's disease. Alzheimers Dement 2011;7:263-9.

25. Wardlaw JM, Smith EE, Biessels GJ, Cordonnier C, Fazekas F, Frayne R, et al. Neuroimaging standards for research into small vessel disease and its contribution to ageing and neurodegeneration. Lancet Neurol 2013;12:822-38.

26. Linn J, Herms J, Dichgans M, Bruckmann H, Fesl G, Freilinger T, et al. Subarachnoid hemosiderosis and superficial cortical hemosiderosis in cerebral amyloid angiopathy. AJNR Am J Neuroradiol 2008;29:184-6.

27. Kang Y, Na DL. Seoul Neuropsychological Screening Battery (SNSB). Incheon: Human Brain Research \& Consulting Co.; 2003.

28. Fazekas F, Kleinert R, Offenbacher H, Schmidt R, Kleinert G, Payer F, et al. Pathologic correlates of incidental MRI white matter signal hyperintensities. Neurology 
$1993 ; 43: 1683-9$.

29. Tzourio-Mazoyer N, Landeau B, Papathanassiou D, Crivello F, Etard O, Delcroix N, et al. Automated anatomical labeling of activations in SPM using a macroscopic anatomical parcellation of the MNI MRI single-subject brain. Neuroimage 2002;15:273-89.

30. Barthel H, Gertz HJ, Dresel S, Peters O, Bartenstein P, Buerger K, et al. Cerebral amyloid-beta PET with florbetaben (18F) in patients with Alzheimer's disease and healthy controls: a multicentre phase 2 diagnostic study. Lancet Neurol 2011;10:424-35.

31. Ahn HJ, Chin J, Park A, Lee BH, Suh MK, Seo SW, et al. Seoul Neuropsychological Screening Battery-dementia version (SNSB-D): a useful tool for assessing and monitoring cognitive impairments in dementia patients. J Korean Med Sci 2010;25:10716.

32. Gurol ME, Viswanathan A, Gidicsin C, Hedden T, Martinez-Ramirez S, Dumas A, et al. Cerebral amyloid angiopathy burden associated with leukoaraiosis: a positron emission tomography/magnetic resonance imaging study. Ann Neurol 2013;73:529-36.

33. Raposo N, Planton M, Peran P, Payoux P, Bonneville F, Lyoubi A, et al. Florbetapir imaging in cerebral amyloid angiopathy-related hemorrhages. Neurology 2017;89:697704.

34. Johnson KA, Gregas M, Becker JA, Kinnecom C, Salat DH, Moran EK, et al. Imaging of amyloid burden and distribution in cerebral amyloid angiopathy. Annals of neurology 2007;62:229-34.

35. Charidimou A, Martinez-Ramirez S, Shoamanesh A, Oliveira-Filho J, Frosch M, Vashkevich A, et al. Cerebral amyloid angiopathy with and without hemorrhage: evidence for different disease phenotypes. Neurology 2015;84:1206-12.

36. Seo SW, Ayakta N, Grinberg LT, Villeneuve S, Lehmann M, Reed B, et al. Regional correlations between [(11)C]PIB PET and post-mortem burden of amyloid-beta pathology in a diverse neuropathological cohort. Neuroimage Clin 2017;13:130-7.

37. Jellinger KA. Alzheimer disease and cerebrovascular pathology: an update. J Neural Transm (Vienna) 2002;109:813-36. 
38. Viswanathan A, Greenberg SM. Cerebral amyloid angiopathy in the elderly. Ann Neurol 2011;70:871-80.

39. Shoamanesh A, Martinez-Ramirez S, Oliveira-Filho J, Reijmer Y, Falcone GJ, Ayres A, et al. Interrelationship of superficial siderosis and microbleeds in cerebral amyloid angiopathy. Neurology 2014;83:1838-43.

40. Martinez-Ramirez S, Romero JR, Shoamanesh A, McKee AC, Van Etten E, Pontes-Neto $\mathrm{O}$, et al. Diagnostic value of lobar microbleeds in individuals without intracerebral hemorrhage. Alzheimers Dement 2015;11:1480-8.

41. Na HK, Park JH, Kim JH, Kim HJ, Kim ST, Werring DJ, et al. Cortical superficial siderosis: a marker of vascular amyloid in patients with cognitive impairment. Neurology $2015 ; 84: 849-55$.

42. Kim YJ, Kim HJ, Park JH, Kim S, Woo SY, Kwak KC, et al. Synergistic effects of longitudinal amyloid and vascular changes on lobar microbleeds. Neurology 2016;87:1575-82.

43. Park JH, Seo SW, Kim C, Kim GH, Noh HJ, Kim ST, et al. Pathogenesis of cerebral microbleeds: In vivo imaging of amyloid and subcortical ischemic small vessel disease in 226 individuals with cognitive impairment. Ann Neurol 2013;73:584-93.

44. Roman GC, Erkinjuntti T, Wallin A, Pantoni L, Chui HC. Subcortical ischaemic vascular dementia. Lancet Neurol 2002;1:426-36.

45. Jang YK, Kim HJ, Lee JS, Kim YJ, Kim KW, Kim Y, et al. Distinctive Clinical Effects of Haemorrhagic Markers in Cerebral Amyloid Angiopathy. Sci Rep 2017;7:15984.

46. Pfeifer LA, White LR, Ross GW, Petrovitch H, Launer LJ. Cerebral amyloid angiopathy and cognitive function: the HAAS autopsy study. Neurology 2002;58:1629-34.

47. Boyle PA, Yu L, Wilson RS, Leurgans SE, Schneider JA, Bennett DA. Person-specific contribution of neuropathologies to cognitive loss in old age. Ann Neurol 2018;83:74-83.

48. Rowe CC, Doré V, Jones G, Baxendale D, Mulligan RS, Bullich S, et al. 18 FFlorbetaben PET beta-amyloid binding expressed in Centiloids 2017;44:2053-9. 


\section{Table 1}

Clinical characteristics of $\mathrm{A} \beta-\mathrm{CAA}, \mathrm{A} \beta+\mathrm{CAA}$, and $\mathrm{A} \beta+\mathrm{AD}$

\begin{tabular}{|c|c|c|c|c|c|c|}
\hline & $\begin{array}{c}\text { Aß- CAA } \\
(\mathbf{n}=22)\end{array}$ & $\begin{array}{c}\mathbf{A \beta}+\mathbf{C A A} \\
(\mathrm{n}=43)\end{array}$ & $\begin{array}{l}\mathbf{A \beta}+\mathbf{A D} \\
(\mathrm{n}=129)\end{array}$ & $\begin{array}{c}p \\
(\mathrm{~A} \beta-\mathrm{CAA} \\
\text { vs. } \mathrm{A} \beta+ \\
\text { CAA) } \\
\end{array}$ & $\begin{array}{c}p \\
(\mathrm{~A} \beta+\mathrm{CAA} \\
\text { vs.A } \beta+ \\
\mathrm{AD}) \\
\end{array}$ & $\begin{array}{c}p \\
(\mathrm{~A} \beta-\mathrm{CAA} \\
\text { vs. A } \beta+ \\
\text { AD) } \\
\end{array}$ \\
\hline Age (years) & $75.3 \pm 7.1$ & $74.4 \pm 8.1$ & $67.1 \pm 10.2$ & 0.661 & $<0.001$ & $<0.001$ \\
\hline Gender (Female, \%) & $12(54.6)$ & $23(53.5)$ & $71(55.0)$ & 0.936 & 0.860 & 0.966 \\
\hline Education (years) & $10.6 \pm 6.1$ & $11.3 \pm 5.2$ & $12.6 \pm 4.4$ & 0.606 & 0.112 & 0.060 \\
\hline \multicolumn{7}{|l|}{ Vascular risk factors } \\
\hline $\begin{array}{l}\text { Hypertension } \\
(\%)\end{array}$ & $10(45.5)$ & $23(53.5)$ & $48(37.2)$ & 0.540 & 0.016 & 0.256 \\
\hline Diabetes (\%) & $8(36.4)$ & $8(18.6)$ & $18(14.0)$ & 0.116 & 0.461 & 0.002 \\
\hline $\begin{array}{l}\text { Hyperlipidemi } \\
\text { a (\%) }\end{array}$ & $5(22.7)$ & $7(16.3)$ & $40(31.0)$ & 0.526 & 0.205 & 0.725 \\
\hline $\begin{array}{l}\text { Cardiac disease } \\
(\%)\end{array}$ & $3(13.6)$ & $3(7.0)$ & $5(3.9)$ & 0.380 & 0.166 & 0.282 \\
\hline Stroke (\%) & $3(13.6)$ & $6(14.0)$ & $1(0.8)$ & 0.972 & 0.093 & 0.153 \\
\hline \multicolumn{7}{|l|}{$\begin{array}{l}\text { Clinical } \\
\text { manifestation }\end{array}$} \\
\hline $\begin{array}{l}\text { Cognitive } \\
\text { impairment } \\
(\%)\end{array}$ & $19(86.4)$ & $40(93.0)$ & N/A & 0.380 & N/A & N/A \\
\hline MMSE* & $22.8 \pm 5.0$ & $19.7 \pm 6.3$ & $16.9 \pm 7.1$ & 0.038 & 0.131 & 0.003 \\
\hline
\end{tabular}

Abbreviation: $\mathrm{A} \beta$, amyloid $\beta$; $\mathrm{CAA}$, cerebral amyloid angiopathy; $\mathrm{AD}$, Alzheimer's disease dementia; n, number; LICH, lobar intracerebral hemorrhage; MMSE, Mini mental status examination; N/A, non-applicable

Values are expressed as means \pm standard deviations or numbers (\%)

*p value after adjusting for age, gender and education 
Table 2

Comparison of CAA and ischemic CSVD burden between A $\beta$ - and A $\beta+$ CAA

\begin{tabular}{|c|c|c|c|}
\hline & $\begin{array}{l}\mathbf{A} \beta-\mathbf{C A A} \\
(n=22)\end{array}$ & $\begin{array}{l}\mathrm{A} \beta+\mathrm{CAA} \\
(\mathrm{n}=\mathbf{4 3})\end{array}$ & $p$ \\
\hline \multicolumn{4}{|l|}{ CAA markers } \\
\hline Presence of $\mathrm{LICH}$ & $4(18.2 \%)$ & $6(14.0 \%)$ & 0.655 \\
\hline Number of CMBs & $3(2,8)$ & $9(2,41)$ & 0.045 \\
\hline Presence of cSS & $2(9.1 \%)$ & $15(34.9 \%)$ & 0.025 \\
\hline \multicolumn{4}{|l|}{ Ischemic CSVD markers } \\
\hline Number of lacunes & $1(0,2)$ & $0(0,1)$ & 0.029 \\
\hline Presence of severe WMH & $10(45.5 \%)$ & $9(20.9 \%)$ & 0.040 \\
\hline
\end{tabular}

Abbreviation: CAA, cerebral amyloid angiopathy; CSVD, cerebral small vessel disease; A $\beta$, amyloid $\beta ; \mathrm{n}$, number; LICH, lobar intracerebral hemorrhage; CMBs, cerebral microbleeds; cSS, cortical superficial siderosis; WMH, white matter hyperintensities

Values are expressed as median (interquartile range) or numbers (\%) 
Table 3

Detailed clinical and imaging characteristics of $\mathrm{A} \beta$ - CAA patients

\begin{tabular}{|c|c|c|c|c|c|c|c|c|c|}
\hline No & $\begin{array}{l}\text { PET } \\
\text { ligand }\end{array}$ & Age & Sex & $\begin{array}{l}\text { MM } \\
\text { SE }\end{array}$ & $\begin{array}{l}\text { Location } \\
\text { of LICH }\end{array}$ & $\begin{array}{l}\text { Presence } \\
\text { of cSS }\end{array}$ & $\begin{array}{l}\text { Number } \\
\text { of lobar } \\
\text { CMBs }\end{array}$ & $\begin{array}{l}\text { Number of } \\
\text { lacunes }\end{array}$ & $\begin{array}{l}\text { Severity of } \\
\text { WMH }\end{array}$ \\
\hline 1 & Florbetaben & 70 & $\mathrm{~F}$ & 17 & $\begin{array}{l}\text { Frontopar } \\
\text { ietal }\end{array}$ & 0 & 16 & 2 & severe \\
\hline 2 & Florbetaben & 60 & M & 18 & Parietal & 0 & 3 & 10 & mild \\
\hline 3 & Florbetaben & 77 & $\mathrm{~F}$ & 17 & $\begin{array}{l}\text { Parieto- } \\
\text { occipital }\end{array}$ & 0 & 32 & 0 & moderate \\
\hline 4 & Florbetaben & 82 & $\mathrm{~F}$ & 19 & Parietal & 0 & 2 & 0 & moderate \\
\hline 5 & Florbetaben & 70 & $\mathrm{~F}$ & 30 & & 1 & 6 & 0 & moderate \\
\hline 6 & Florbetaben & 78 & $\mathrm{~F}$ & 24 & & 1 & 1 & 2 & moderate \\
\hline 7 & $\mathrm{PiB}$ & 71 & M & 23 & & 0 & 1 & 2 & severe \\
\hline 8 & $\mathrm{PiB}$ & 80 & M & 27 & & 0 & 2 & 0 & moderate \\
\hline 9 & $\mathrm{PiB}$ & 78 & $\mathrm{~F}$ & 27 & & 0 & 5 & 2 & severe \\
\hline 10 & $\mathrm{PiB}$ & 72 & $\mathrm{~F}$ & 15 & & 0 & 12 & 0 & severe \\
\hline 11 & $\mathrm{PiB}$ & 79 & M & 18 & & 0 & 8 & 7 & severe \\
\hline 12 & Florbetaben & 87 & $\mathrm{~F}$ & 20 & & 0 & 9 & 1 & mild \\
\hline 13 & Florbetaben & 70 & $\mathrm{~F}$ & 27 & & 0 & 7 & 2 & severe \\
\hline 14 & Florbetaben & 88 & M & 18 & & 0 & 3 & 2 & mild \\
\hline 15 & Florbetaben & 78 & M & 29 & & 0 & 2 & 1 & severe \\
\hline 16 & Florbetaben & 73 & M & 27 & & 0 & 3 & 0 & mild \\
\hline 17 & Florbetaben & 87 & M & 25 & & 0 & 2 & 1 & severe \\
\hline 18 & Florbetaben & 73 & M & 29 & & 0 & 2 & 11 & severe \\
\hline 19 & Florbetaben & 67 & $\mathrm{~F}$ & 18 & & 0 & 2 & 0 & moderate \\
\hline 20 & Florbetaben & 75 & $\mathrm{~F}$ & 24 & & 0 & 25 & 0 & moderate \\
\hline 21 & Florbetaben & 66 & M & 19 & & 0 & 2 & 0 & mild \\
\hline 22 & Florbetaben & 76 & $\mathrm{~F}$ & 30 & & 0 & 8 & 13 & severe \\
\hline
\end{tabular}

Abbreviation: $\mathrm{A} \beta$, amyloid $\beta$; $\mathrm{CAA}$, cerebral amyloid angiopathy; PET, Positron emission tomography; PiB, Pittsburg B compound; MMSE, mini-mental state examination; LICH, lobar intracerebral hemorrhage; cSS, cortical superficial siderosis; CMBs, cerebral microbleeds; WMH, white matter hyperintensities 


\section{Table 4}

Comparison of cognitive trajectory between $A \beta$ - and $A \beta+C A A$

\begin{tabular}{|c|c|c|c|c|c|c|}
\hline & \multicolumn{3}{|c|}{ Baseline cognition } & \multicolumn{3}{|c|}{ Longitudinal cognitive change } \\
\hline & $\begin{array}{l}\text { Aß- CAA } \\
(n=22)\end{array}$ & $\begin{array}{l}\mathbf{A \beta}+\mathbf{C A A} \\
(\mathrm{n}=43)\end{array}$ & $p^{*}$ & B & SE & $p^{\dagger}$ \\
\hline \multicolumn{7}{|l|}{ Attention } \\
\hline Digit span forward (9) & $5.0 \pm 1.2$ & $5.4 \pm 1.3$ & 0.344 & -0.02 & 0.06 & 0.686 \\
\hline Digit span backward (8) & $3.1 \pm 1.2$ & $3.0 \pm 1.3$ & 0.769 & -0.14 & 0.07 & 0.049 \\
\hline \multicolumn{7}{|l|}{ Language } \\
\hline BNT (60) & $37.7 \pm 9.5$ & $30.4 \pm 12.7$ & 0.014 & -2.52 & 0.40 & $<0.001$ \\
\hline \multicolumn{7}{|l|}{ Visuospatial function } \\
\hline RCFT copy (36) & $23.4 \pm 11.1$ & $20.5 \pm 10.8$ & 0.348 & -1.97 & 0.47 & $<0.001$ \\
\hline \multicolumn{7}{|l|}{ Memory } \\
\hline SVLT immediate recall (36) & $13.9 \pm 4.7$ & $11.5 \pm 5.4$ & 0.095 & -1.15 & 0.26 & $<0.001$ \\
\hline SVLT delayed recall (12) & $2.6 \pm 2.4$ & $1.6 \pm 2.6$ & 0.116 & -0.20 & 0.11 & 0.062 \\
\hline SVLT recognition (24) & $18.5 \pm 2.9$ & $17.0 \pm 4.3$ & 0.211 & 6.01 & 5.58 & 0.281 \\
\hline RCFT immediate recall (36) & $6.3 \pm 6.3$ & $3.9 \pm 4.8$ & 0.101 & -0.08 & 0.29 & 0.005 \\
\hline RCFT delayed recall (36) & $5.9 \pm 5.5$ & $4.2 \pm 5.1$ & 0.224 & -1.01 & 0.25 & $<0.001$ \\
\hline RCFT recognition (24) & $17.4 \pm 3.3$ & $16.8 \pm 3.1$ & 0.557 & -0.27 & 0.19 & 0.144 \\
\hline \multicolumn{7}{|l|}{ Frontal/executive function } \\
\hline COWAT animal & $9.5 \pm 5.1$ & $9.0 \pm 4.4$ & 0.752 & -0.29 & 0.22 & 0.189 \\
\hline COWAT supermarket & $7.3 \pm 4.3$ & $9.9 \pm 5.8$ & 0.075 & -1.17 & 0.34 & 0.001 \\
\hline COWAT phonemic & $15.0 \pm 11.5$ & $13.0 \pm 9.1$ & 0.496 & -.091 & 0.56 & 0.104 \\
\hline Stroop color reading (112) & $46.9 \pm 29.3$ & $38.2 \pm 25.3$ & 0.303 & -3.87 & 1.12 & 0.001 \\
\hline MMSE (30) & $22.8 \pm 5.0$ & $19.7 \pm 6.3$ & 0.038 & -1.46 & 0.23 & $<0.001$ \\
\hline CDR-SOB & $3.5 \pm 5.0$ & $4.8 \pm 4.1$ & 0.236 & 0.70 & 0.16 & $<0.001$ \\
\hline
\end{tabular}

Abbreviation: $\mathrm{A} \beta$, amyloid $\beta$; CAA, cerebral amyloid angiopathy; $\mathrm{n}$, number; $\mathrm{SE}$, standard error; $\mathrm{BNT}$, Boston naming test; RCFT, Rey copy figure test; SVLT, Seoul Verbal Learning Test; COWAT, Controlled Oral Word Association Test; MMSE, mini-mental state examination; CDR-SOB, clinical deterioration ratingsum of boxes

Values are expressed as means \pm standard deviations

* Difference between groups by analysis of covariance using age, gender, and education as covariates

${ }^{\dagger}$ Effect of $A \beta$ positivity on longitudinal cognitive changes obtained from linear mixed effect model 


\section{Table 5}

Previous studies reporting $A \beta$ positivity in probable CAA

\begin{tabular}{|c|c|c|c|c|c|c|}
\hline Study & $\begin{array}{l}\text { Number of } \\
\text { patients }\end{array}$ & CAA diagnosis & $\begin{array}{l}\text { Clinical } \\
\text { manifestation }\end{array}$ & $\begin{array}{l}\mathrm{A} \beta \text { PET } \\
\text { ligand }\end{array}$ & $\begin{array}{l}\text { Determination of } \mathrm{A} \beta \\
\text { positivity }\end{array}$ & $\begin{array}{l}A \beta \text { positivity } \\
(\%)\end{array}$ \\
\hline Current study & $\mathrm{n}=65$ & MRI & $\begin{array}{l}\text { Memory } \\
\text { impairment }(n=59) \\
\text { LICH }(n=6)\end{array}$ & $\begin{array}{l}\mathrm{PiB}(\mathrm{n}=15) \\
\text { florbetaben } \\
(\mathrm{n}=50)\end{array}$ & $\begin{array}{l}\text { SUVR cutoff: } 1.5 \\
\text { (PiB) } \\
\text { Visual (florbetaben) }\end{array}$ & $43 / 65(66 \%)$ \\
\hline $\begin{array}{l}\text { Johnson et al[34], Ann } \\
\text { Neurology, } 2007\end{array}$ & $\mathrm{n}=6$ & $\begin{array}{l}\text { Pathology }(n=4) \\
\text { MRI }(n=2)\end{array}$ & $\begin{array}{l}\text { Seizure }(n=4) \\
\text { LICH }(n=2)\end{array}$ & $\mathrm{PiB}$ & Visual & $6 / 6(100 \%)$ \\
\hline $\begin{array}{l}\text { Ly et al, Neurology, } \\
2010[6]\end{array}$ & $\mathrm{n}=8$ & MRI & $\mathrm{LICH}$ & $\mathrm{PiB}$ & DVR cutoff: 1.44 & $7 / 8(88 \%)$ \\
\hline $\begin{array}{l}\text { Gurol et al, Ann } \\
\text { Neurology, 2013[32] }\end{array}$ & $\mathrm{n}=42$ & $\begin{array}{l}\text { MRI + supporting } \\
\text { pathology }(n=14) \\
\text { MRI }(n=28)\end{array}$ & $\begin{array}{l}\text { LICH }(n=23) \text {, other } \\
(n=19) \text { such as gait } \\
\text { disorder or seizures }\end{array}$ & $\mathrm{PiB}$ & DVR cutoff: 1.22 & $29 / 42(69 \%)$ \\
\hline $\begin{array}{l}\text { Baron et al, JCBFM, } \\
\text { 2014[4] }\end{array}$ & $\mathrm{n}=11$ & MRI & LICH & $\mathrm{PiB}$ & DVR cutoff: 1.22 & $9 / 11(82 \%)$ \\
\hline $\begin{array}{l}\text { Gurol et al, Neurology, } \\
2016[5]\end{array}$ & $\mathrm{n}=10$ & MRI & $\mathrm{LICH}$ & florbetapir & Visual & $10 / 10(100 \%)$ \\
\hline $\begin{array}{l}\text { Raposo et al. Neurology, } \\
\text { 2017[33] }\end{array}$ & $\mathrm{n}=15$ & $\begin{array}{l}\text { MRI + supporting } \\
\text { pathology }(n=2) \\
\text { MRI }(n=13)\end{array}$ & $\mathrm{LICH}$ & florbetapir & Visual & $9 / 15(60 \%)$ \\
\hline
\end{tabular}

Abbreviation: $\mathrm{A} \beta$, amyloid $\beta$; CAA, cerebral amyloid angiopathy; PET, positron emission tomography; n, number; MRI, magnetic resonance imaging; LICH, lobar intracerebral hemorrhage; PiB, Pittsburg B compound; SUVR, standardized uptake value ratio; DVR, distribution volume ratio 
Figure legends

(a)

100

80

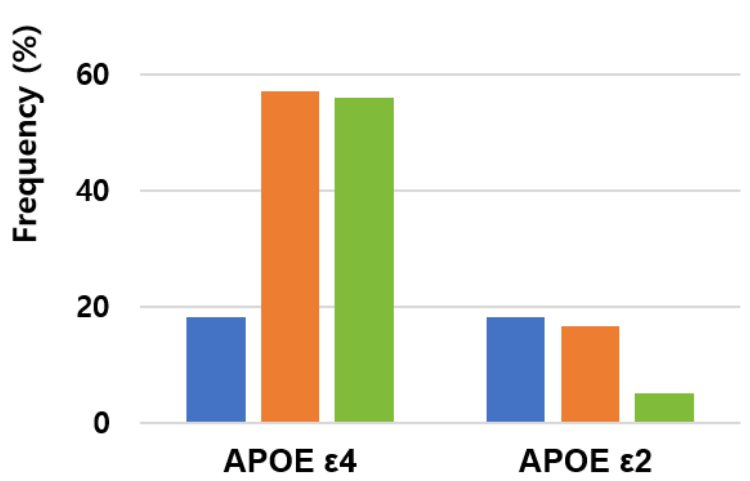

$\square A \beta-C A A \backsim A \beta+C A A \backsim A \beta+A D$ (b)

100

80

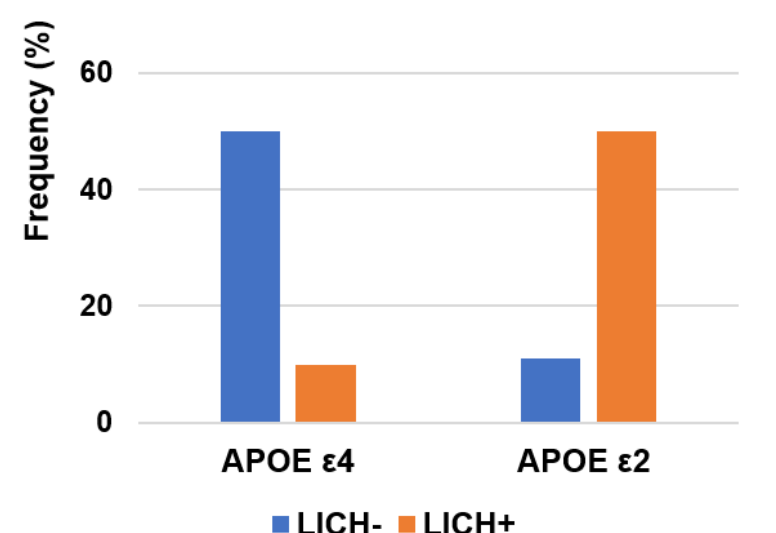

(c)

100

80

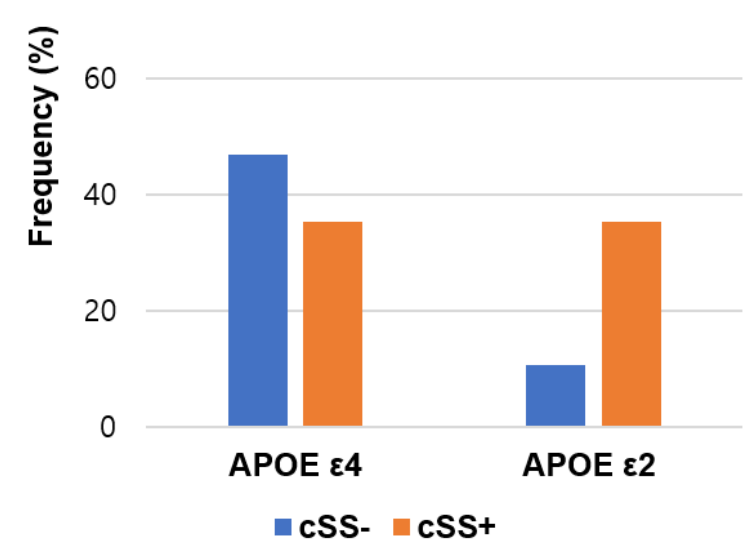

Fig. 1 The frequency of $A P O E \varepsilon 4$ or $\varepsilon 2$ carriers by (a) A $\beta$ positivity and the presence of CAA hemorrhagic markers such as (b) LICH and (c) cSS

Abbreviation: APOE, apolipoprotein E; CAA, cerebral amyloid angiopathy markers; A $\beta$, amyloid $\beta$; AD, Alzheimer's disease dementia; LICH, lobar intracerebral hemorrhage; cSS, cortical superficial siderosis 

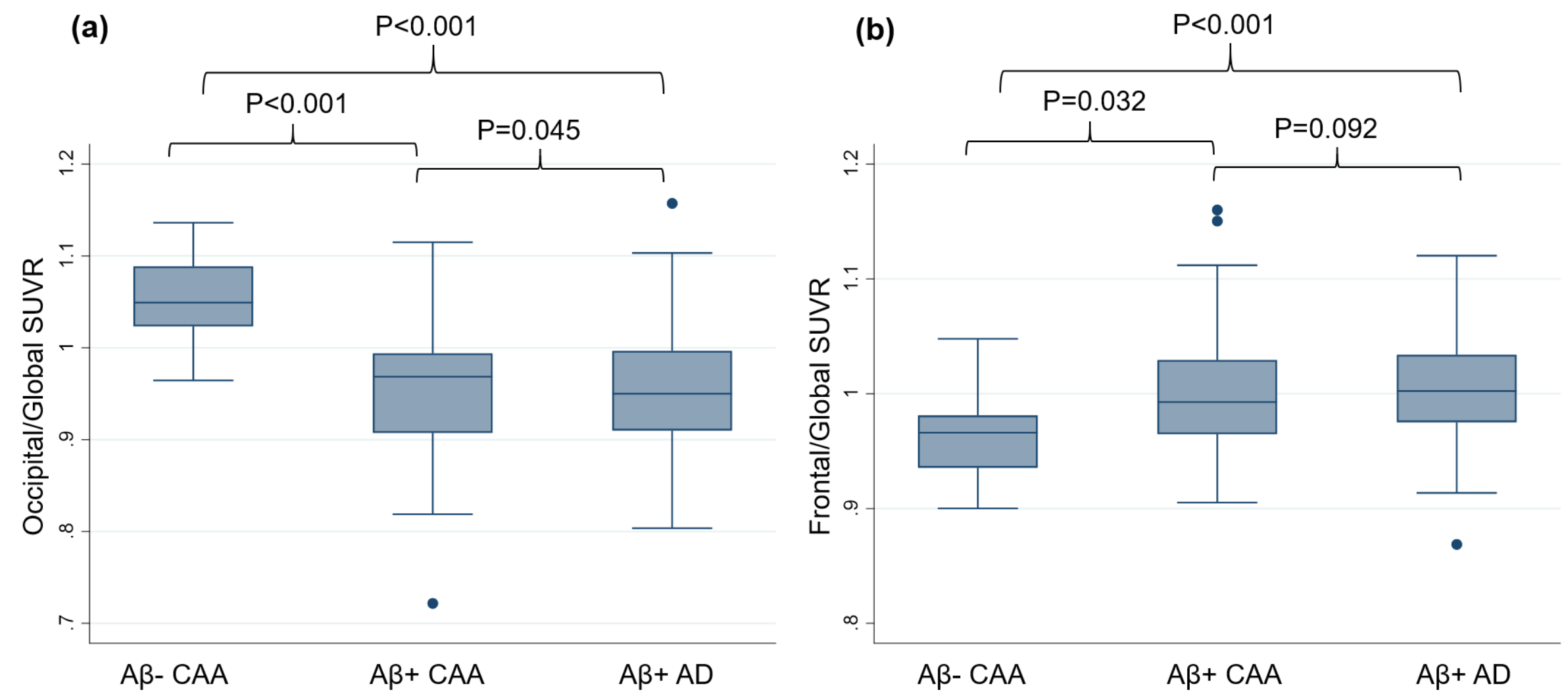

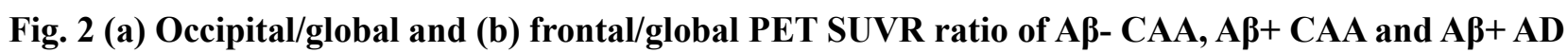

Abbreviation: $A \beta$, amyloid $\beta$; PET, positron emission tomography; SUVR, standardized uptake value ratio; CAA, cerebral amyloid angiopathy; AD, Alzheimer's disease dementia 


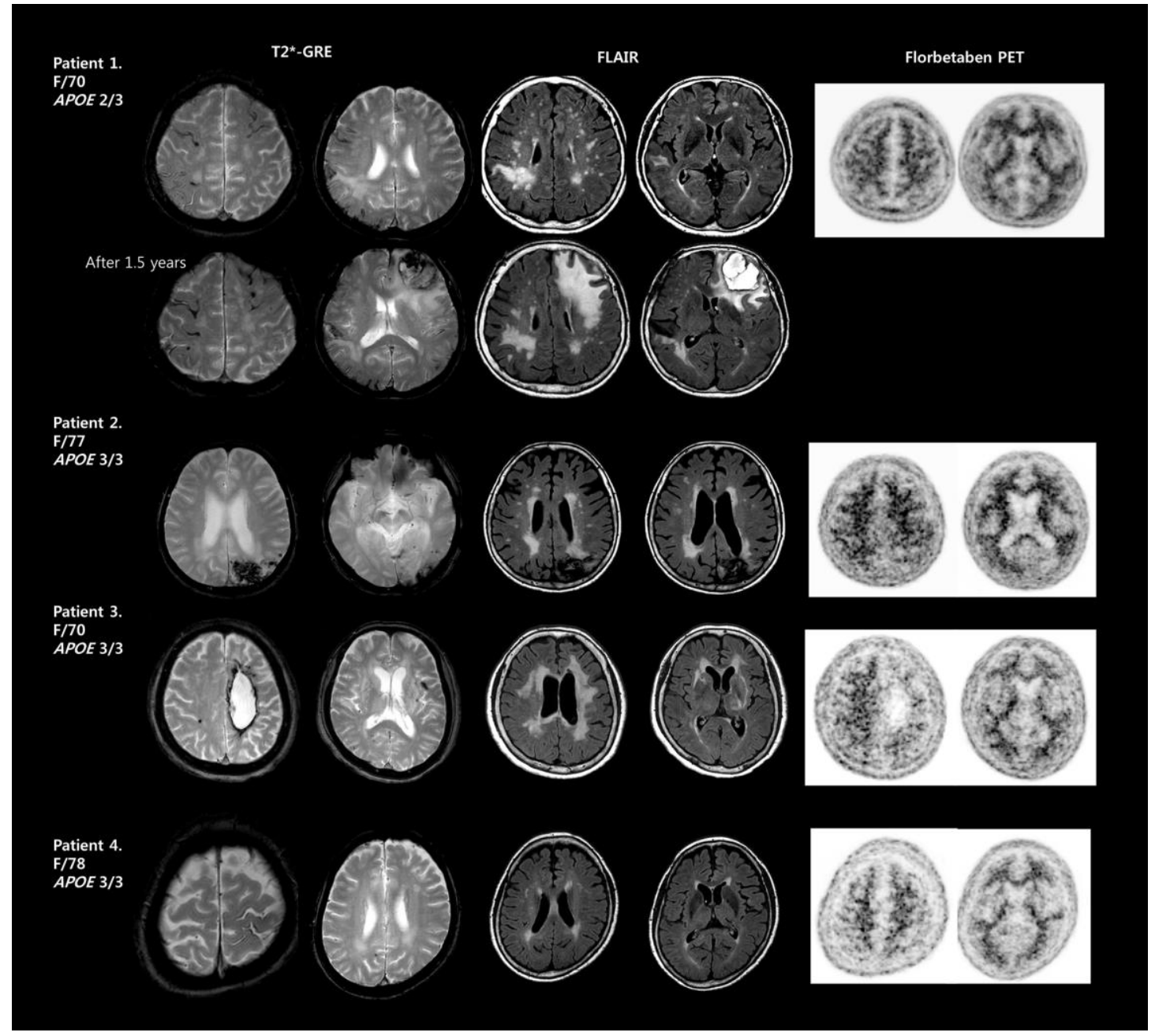

Fig. 3 Typical cases of A $\beta$ - CAA patients

Abbreviation: $\mathrm{A} \beta$, amyloid $\beta$; $\mathrm{CAA}$, cerebral amyloid angiopathy; $\mathrm{APOE}$, apolipoprotein $\mathrm{E}$; GRE, gradient echo; FLAIR, Fluid-attenuated inversion recovery; PET, positron emission tomography 

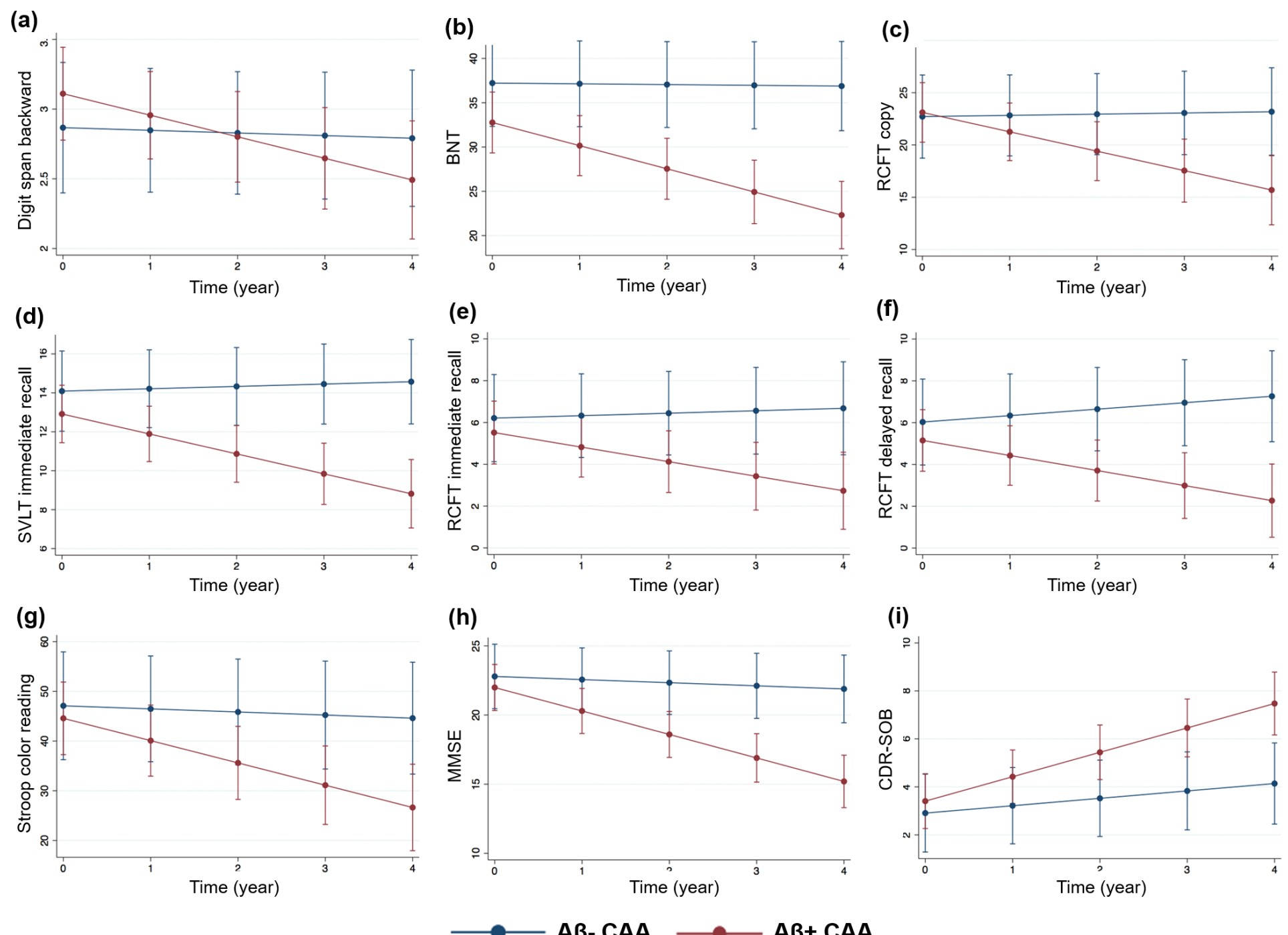
Fig. 4 Distinctive cognitive decline according to A $\beta$ positivity ((a) Digit span backward; (b) BNT; (c) RCFT copy; (d) SVLT immediate recall; (e) RCFT immediate recall; (f) RCFT delayed recall; (g) Stroop test color reading; (h) MMSE; (i) CDR-SOB)).

Abbreviation: A $\beta$, amyloid $\beta$; CAA, cerebral amyloid angiopathy; BNT, Boston naming test; RCFT, Rey copy figure test; SVLT, Seoul Verbal Learning Test; MMSE, mini-mental state examination; CDR-SOB, clinical deterioration rating-sum of box

$\mathrm{Y}$ axis represents the predicted neuropsychological scores for each follow up year derived from the predicted model equation using a linear mixed effect model 